\title{
Posterior Spinal Fusion With Multilevel Posterolateral Convex Disc Releases for the Treatment of Severe Thoracolumbar Scoliosis
}

\author{
CHRISTOPHER MIKHAIL, MD, ROBERT BROCHIN, MD, LILY EAKER, BA, BARON S. LONNER, MD \\ Mount Sinai Hospital, New York, New York
}

\begin{abstract}
Background: Severe, rigid thoracolumbar scoliosis presents a surgical challenge to achieve 3-dimensional correction, maximize distal motion segments, and avoid operative morbidity conferred by combined anterior-posterior approaches or 3-column osteotomies. We present a new approach for releasing these curves, using multilevel posterolateral convex disc release (PCDR) and posterior instrumented fusion.

Methods: There were 3 adults and 1 adolescent (mean age, 31.8 years; 2 females) with severe progressive thoracic and transforaminal lumbar (major) idiopathic scoliosis (IS) who were treated with 3-level PCDR, multiple posterior column osteotomies, and posterior instrumented thoracolumbar fusion with all-pedicle screw constructs.

Results: Restoration of global coronal and sagittal alignment was achieved for all patients (minimum 2-year follow-up). Lowest instrumented vertebra (LIV) was L4 in 2 patients and L3 in the remaining 2 . All except 1 were fused to the lower end vertebra. Postoperatively, mean thoracolumbar curve was reduced from $77.3^{\circ}$ (range, $69^{\circ}-91^{\circ}$ ) to $21.8^{\circ}$ $(72 \% \Delta)$, LIV tilt decreased from $26.8^{\circ}$ to $8.3^{\circ}$, and LIV translation improved $(2.5-1.2 \mathrm{~cm} ; 58 \% \Delta)$, whereas lumbar lordosis remained unchanged. Average central sacral vertical line shift measured via $\mathrm{C} 7$ sagittal vertical axis changed from 1.4 to $-0.7 \mathrm{~cm}$. There were no complications except for dysesthesias in the lower extremity on the side of the PCDR in 1 patient, which resolved after 3 months.

Conclusions: Severe thoracolumbar IS presents a surgical challenge to achieve 3-dimensional correction, minimize fusion levels, and avoid procedural morbidity. PCDR is a novel technique that may facilitate this correction with minimal procedure-related morbidity.
\end{abstract}

Lumbar Spine

Keywords: thoracolumbar scoliosis, new technique, posterolateral convex disc release, feasibility study

\section{INTRODUCTION}

Surgical management of severe, rigid thoracolumbar scoliosis in the skeletally mature adolescent and adult presents a surgical challenge. A number of surgical approaches and techniques have been used for severe, rigid scoliosis, each with advantages and drawbacks, predominantly due to approach-related morbidity. Historically, combined anterior disc release with posterior fusion has been commonly used to address rigid thoracolumbar scoliosis. Despite the positive results surrounding the anterior approach both biomechanically and clinically, ${ }^{1-4}$ this approach has fallen out of favor because of perceived or verified morbidity, including pulmonary function impairment, vascular injury, postoperative ileus, and the need for chest tubes, leading to prolonged hospitalization and possible abdominal hernia or pseudohernia. ${ }^{5}$ These concerns have exhorted sur- geons to champion the posterior-only approach as a means to obviate the potential morbidity. ${ }^{6-11}$

Although the posterior-alone approach does carry the advantage of evading potential pulmonary impairment and other morbidities, it may be associated with longer fusions and more distal lowest instrumented vertebrae compared with the anterior-only approach or combined approaches, leading to subsequent loss of distal motion segments, and may not result in adequate deformity correction. $^{12-15}$ Posterior-based osteotomies from posterior column osteotomies to pedicle subtraction osteotomy and, finally, to vertebral column resection may facilitate operative goals but are associated with significant complications, including neurologic injury, dural tears, and pseudarthrosis. ${ }^{16}$

The rationale for maintaining the maximal number of unfused motion segments below or 
above is to maintain as much clinical motion as possible and also to minimize the transfer of stresses to the adjacent levels, which may accelerate the progression of disc degeneration. ${ }^{7,8,10,11,17-19}$

The purpose of the present study is to evaluate the feasibility of a novel technique we have developed for releasing rigid thoracolumbar curvature while avoiding the morbidity associated with anterior approaches or more advanced posterior osteotomies to facilitate curve correction and maximize remaining motion segments. We present the posterolateral convex disc release (PCDR): a multilevel anterior column-shortening technique performed via a transforaminal lumbar interbody fusion (TLIF) equivalent approach that creates substantial spinal flexibility for posterior reconstruction under a single anesthetic. Four illustrative cases are presented here, with an emphasis on indications and outcome.

\section{METHODS}

Institutional Review Board approval from Mount Sinai Hospital was obtained for this retrospective study investigating the radiographic and clinical course of 4 patients with severe progressive thoracic and major thoracolumbar idiopathic scoliosis undergoing 3-level PCDR (T12-L3 or L1-L4), multiple posterior column osteotomies, and posterior instrumented thoracolumbar fusion with all-pedicle screw constructs.

Radiographic and clinical data were obtained preoperatively, postoperatively, and at follow-up. The following radiographic parameters were measured by the same observer: coronal Cobb angles of the major thoracolumbar and minor structural thoracic curvatures, respectively; thoracic kyphosis, LIV tilt and translation, sagittal and coronal global alignment, and maximal correction (coronal curve flexibility) on preoperative side-bending films. Comparisons were made of the levels between the LIV and stable vertebrae, touched vertebrae, Cobb end vertebrae (CEV), and neutral vertebrae.

Total lumbar lordosis (LL) was measured from T12 to S1. Thoracolumbar sagittal alignment (TL) was measured from T10 to L2. Thoracic kyphosis was measured from T5 to T12. The C7 sagittal vertical axis (C7SVA, the horizontal distance between the $\mathrm{C}-7$ plumb line and the posterosuperior corner of the S-1 vertebral body) was used to measure global sagittal alignment. The central sacral vertical line (CSVL, the horizontal distance between the C-7 plumb line and the central sacral vertical line) was used to measure global coronal alignment. The LIV tilt was measured as the angle between the horizontal and a line parallel to the lower end plate of the LIV. The LIV translation was measured as the distance (in $\mathrm{cm}$ ) from the center of the LIV to the CSVL. Preoperative neutral vertebra was defined as the most cephalad vertebra below the apex of the major curve whose pedicles are symmetrically located within the lateral borders of the vertebral body, and the stable vertebra (SV) was defined as the most cephalad vertebra at or immediately below the end vertebra $(\mathrm{EV})$ of the major curve that is most closely bisected by the CSVL. Operative and perioperative outcomes, complications, and morbidity were retrospectively collected.

The PCDR technique performed essentially uses a TLIF approach on the convex side of the curve being corrected and including 3 discs to the level of the LIV. First, the posterior elements of the spine are exposed, prior to instrumentation, and a grade II osteotomy of the relevant spinal segment is performed. ${ }^{20}$ This involves the resection of the inferior (medial) facets as well as the cephalad portion of the superior facet to the level of the pedicle as well as the ligamentum flavum at a given spinal segment. ${ }^{20}$ After this osteotomy is performed the intervertebral disc is then accessed in a familiar TLIF approach in which the pars interarticularis is removed on the convexity. The exiting nerve root must be identified and avoided, and the spinal cord or cauda equina (traversing nerve root) should be protected with a retractor. This approach differs from the typical TLIF in that dissection around the anterolateral annulus to the midline is performed and a small ribbon malleable retractor is placed around the disc to protect the viscera and large blood vessels. The annulus can then be incised and nuclear material removed. In this technique $50 \%$ to $60 \%$ of the anterior annulus and corresponding nuclear material is removed. (Figure 1). Indications for this technique include severe, rigid thoracolumbar scoliosis with flexibility to greater than or equal to $35^{\circ}$ correction on side bending, severe rotational deformity greater than $20^{\circ}$ on inclinometer, and/or a desire to save a distal fusion level with rotational deformity of proposed lowest instrumented vertebrae greater or equal to Nash-Moe 2. 


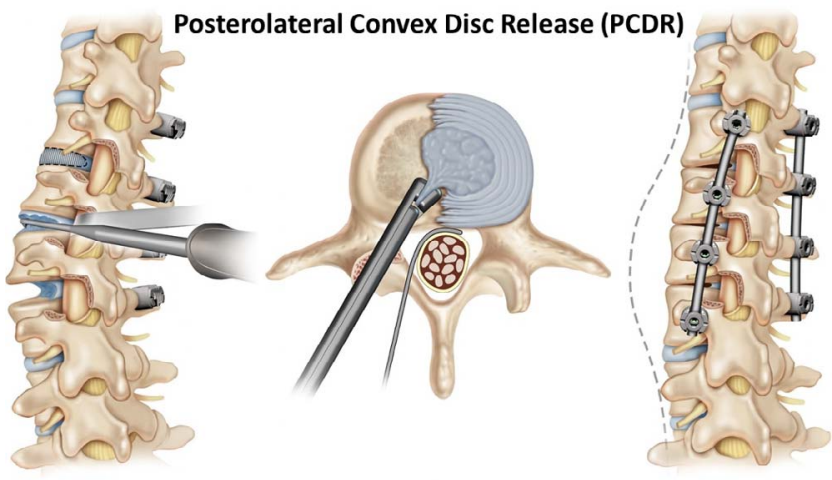

Figure 1. Illustration of PCDR technique.

\section{RESULTS}

The case series included 4 patients ( 2 female, 2 male) - 3 skeletally mature adults ( 2 female, 1 male) and 1 skeletally immature adolescent (male), with a mean age of 31.8 years and a mean of 2.3 years of follow-up. All patients had a diagnosis of thoracic and major thoracolumbar idiopathic scoliosis, and Lenke $6 \mathrm{CN}$ curves or their adult equivalents (Table $1)$.

All patients underwent a 3-level PCDR (2 from T12-L3, and 2 from L1-L4), multiple posterior column osteotomies, and posterior instrumented thoracolumbar fusion with all-pedicle screw constructs (Figure 2 and Figure 3).

Restoration of global coronal and sagittal alignment was achieved for all 4 patients with a minimum of 2-year follow-up (Table 2). Lowest instrumented vertebra (LIV) was L4 in 2 of the adults and L3 in the other 2 patients. Three patients were fused to the distal CEV (LEV) or LEV-1. The last touched vertebra was L4 in 3 patients and L3 in 1 patient. The stable vertebra was deemed to be in L5 in all 4 patients. One patient with disc degeneration and subsequent laterolisthesis was fused to 1 level below the LEV. This resulted in saving a level in 2 of the 4 patients.

After surgery, the mean thoracolumbar curve was reduced from $77.3^{\circ}\left(\mathrm{SD}, 9^{\circ}\right)$ to $21.8^{\circ}\left(\mathrm{SD}, 4.9^{\circ}\right)$, a $72 \%$ (SD, 6\%) correction. The LIV tilt was decreased from $26.8^{\circ}\left(\mathrm{SD}, 9.0^{\circ}\right)$ to $8.3^{\circ}$ (SD, $1.5^{\circ}$ ), a $66 \%$ change. The LIV translation was also improved by a $58 \%$ decrease, from $2.5 \mathrm{~cm}$ (SD, 1 $\mathrm{cm})$ to $1.2 \mathrm{~cm}(\mathrm{SD}, 0.8 \mathrm{~cm})$ (Table 3$)$. The LL was maintained $\left(57.0^{\circ}\right.$ vs $\left.57.8^{\circ}\right)$. The C7SVA changed from $1.4 \mathrm{~cm}(\mathrm{SD}, 0.9 \mathrm{~cm})$ to $0.7 \mathrm{~cm}(\mathrm{SD}, 0.3 \mathrm{~cm})$ Mean thoracolumbar clinical axial plane rotation measured via inclinometer improved from $25^{\circ}$ to $6^{\circ}$.

The thoracic angle of trunk rotation (ATR) improved from $9.3^{\circ}$ to $4.8^{\circ}\left(\mathrm{SD}, 3.8^{\circ}\right)$, and the thoracolumbar ATR improved from $24.5^{\circ}$ to $4^{\circ}$ $\left(\mathrm{SD}, 3^{\circ}\right)$.

There was 1 immediate postoperative complication. One patient experienced dysesthesias in the lower extremity ipsilateral to the side of the PCDR, which resolved completely after 3 months. There were no intraoperative complications: vascular injuries or dural tears. There were no long-term complications and no reoperations throughout the follow-up period.

\section{DISCUSSION}

The challenge the surgeon faces when addressing severe, rigid thoracolumbar scoliosis is to achieve a 3-dimensional correction while saving distal motion segments, leveling the LIV, ${ }^{21}$ and avoiding approach-related morbidity. A number of techniques have been used to address severe, rigid scoliosis, including anterior disc release (or anterior discectomy) and posterior-based osteotomies with posterior instrumentation, Anterior discectomy has been shown to create greater axial instability that can

Table 1. Demographics and operative characteristics.

\begin{tabular}{|c|c|c|c|c|c|}
\hline & \multicolumn{4}{|c|}{ Patient } & \multirow[b]{2}{*}{ Mean } \\
\hline & 1 & 2 & 3 & 4 & \\
\hline Sex & $\mathrm{M}$ & M & $\mathrm{F}$ & $\mathrm{F}$ & $50 \% \mathrm{~F}$ \\
\hline Age, y & 17 & 37 & 28 & 45 & 32 \\
\hline Skeletal maturity & Immature & Mature & Mature & Mature & \\
\hline Lenke & $6 \mathrm{CN}$ & $6 \mathrm{CN}$ & $6 \mathrm{CN}$ & $6 \mathrm{CN}$ & \\
\hline Follow-up, y & 2 & 2.2 & 2 & 3.1 & 2.3 \\
\hline No. of levels fused & 13 & 14 & 14 & 14 & 13.75 \\
\hline Operative time, $\min$ & 360 & 340 & $\mathrm{NC}$ & 345 & 348.33 \\
\hline EBL, cc & 3000 & 1220 & 800 & 800 & 1455 \\
\hline Need for transfusion, $\mathrm{Y} / \mathrm{N}$ & $\begin{array}{l}\text { Y (1500 cell saver/ } \\
3 \text { units of PRBC) }\end{array}$ & $\mathrm{N}(610$ cell saver $)$ & $\begin{array}{l}\text { Y ( } 385 \text { cell saver/ } \\
2 \text { units of PRBC) }\end{array}$ & $\begin{array}{l}\text { Y ( } 355 \text { cell saver } / 1 \text { unit of } \\
\text { designated blood })\end{array}$ & NA \\
\hline Complications, Y/N & $\mathrm{N}$ & $\mathrm{N}$ & $\mathrm{N}$ & $\mathrm{N}$ & $\mathrm{N}$ \\
\hline
\end{tabular}

Abbreviations: NC, not collected; EBL, Estimated Blood Loss; PRBC, Packed Red Blood Cells; NA, not applicable. 


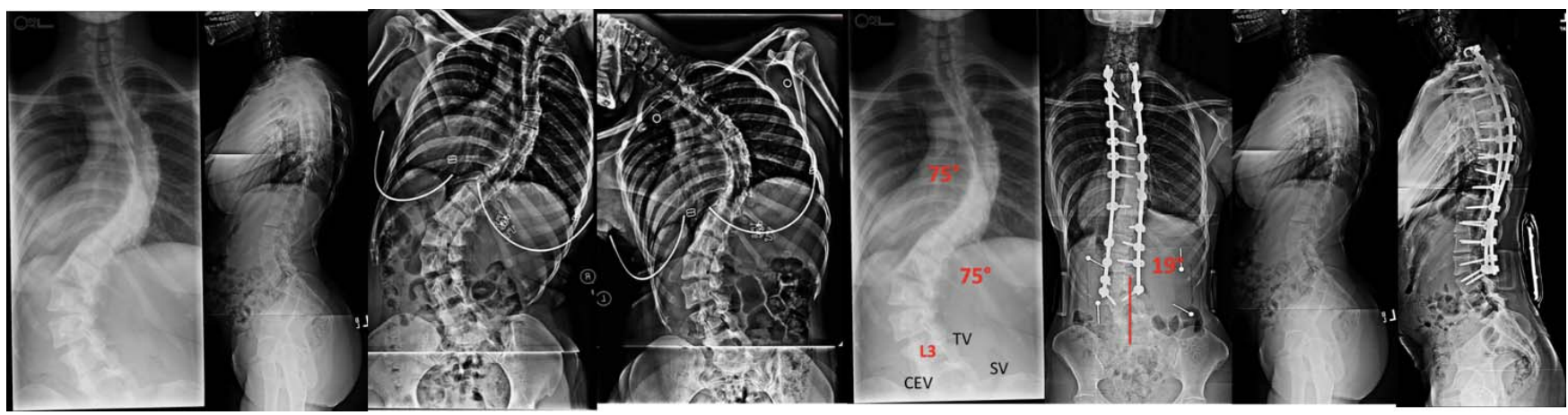

Figure 2. A 28-year-old female patient underwent posterior spinal fusion with posterior column osteotomies and PCDR T12 to L3 with excellent clinical outcomes at 1 year of follow-up. Fusion to touched vertebrae, 1 level cephalad to the CEV.

be used to derotate the spine when biomechanically compared to posterior releases. ${ }^{22}$

Use of anterior approaches for scoliosis either as stand-alone procedures or in combination with posterior surgery has declined because of associated pulmonary or other approach-related morbidity. Anterior stand-alone procedures for thoracolumbar curvatures have been associated with shorter fusions and more cephalad LIV than posterior procedures. ${ }^{12,23-25}$ Matched comparisons between anterior and posterior approaches in Lenke 5C curves demonstrated equivalent curve correction and reduced hospital stays with the posterior approach versus anterior fusion in moderate thoracolumbar scoliosis. ${ }^{26}$ Posterior approaches have been reported to achieve results at least equivalent to those of combined approaches in severe, rigid thoracic scoliosis. ${ }^{8,27}$ However, posterior constructs may be associated with more distal fusion that can increase the rate of adjacent segment degeneration, with fusion to L4 associated with a $27 \%$ risk of developing degeneration at 10 years. ${ }^{21}$ Criteria for fusion to L3 versus L4 with standard techniques were suggested by Erdem et al. ${ }^{28}$

In this case series of patients with severe rigid thoracolumbar scoliosis, we used a novel technique involving a posterolateral convex disc release followed by posterior instrumentation. PCDR allows for an improved release compared with posterior-only releases and perhaps approaches the benefits of an anterior disc release through a posterolateral approach similar to that used for a TLIF. The increased flexibility attainable through PCDR theoretically can allow for shorter fusion constructs and sparing of distal motion segments as well as improved coronal, sagittal, and axial plane correction, while also avoiding anterior approachrelated morbidity.

Although the effects of various releases, including discectomy, facetectomy, and rib head resections, have been investigated in cadavers in the thoracic spine, the amount of curve correction achievable
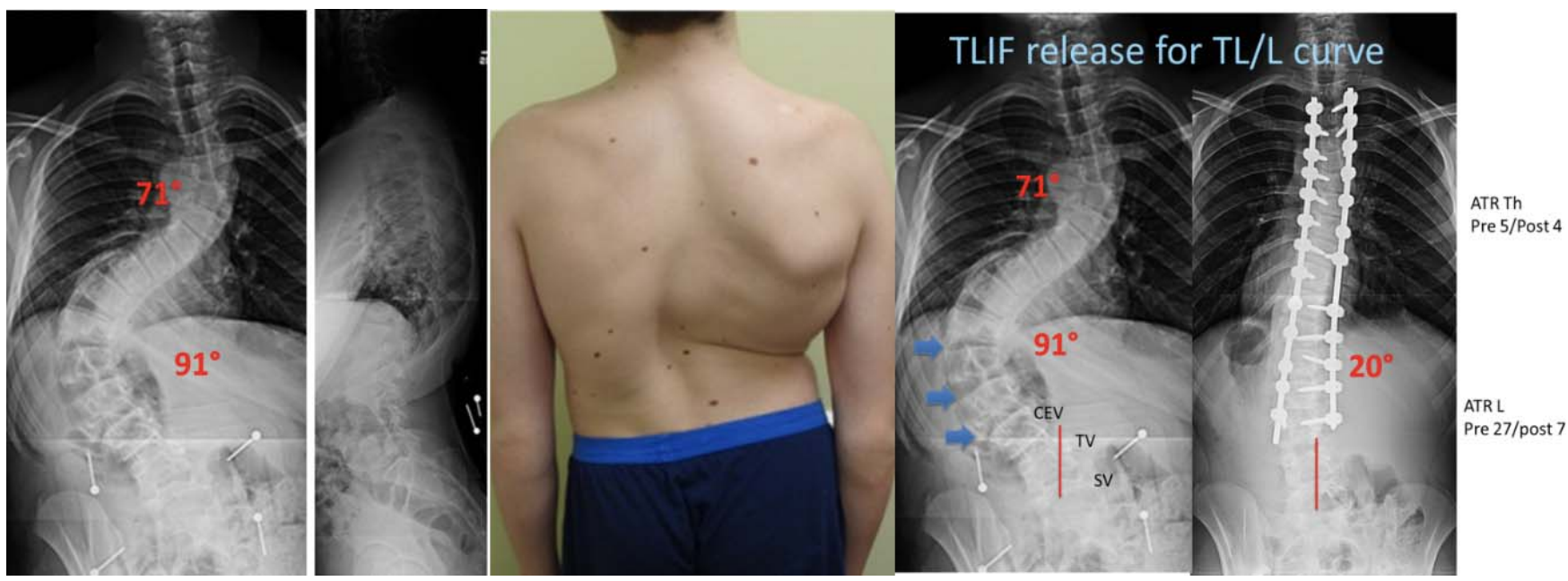

Figure 3. A 17-year-old male patient underwent posterior spinal fusion with posterior column osteotomies and PCDR T12 to L3 with excellent clinical outcomes at 2 years of follow-up. Fusion to CEV, 1 level cephalad to the touched vertebrae. 
Table 2. Changes in radiographic parameters.

\begin{tabular}{|c|c|c|c|c|c|c|}
\hline & $17 \mathrm{y} / \mathbf{M}$ & $37 \mathbf{y} / \mathbf{M}$ & $28 \mathrm{y} / \mathrm{F}$ & $45 \mathrm{y} / \mathrm{F}$ & Mean & SD \\
\hline Preoperative main thoracic, ${ }^{\circ}(\%$ flexibility $)$ & $71(24)$ & $44(16)$ & $71(25)$ & $48(25)$ & $58.5(22.5)$ & $14.5(4.4)$ \\
\hline Postoperative main thoracic, ${ }^{\circ}(\%$ correction $)$ & $27(62)$ & $20(55)$ & $15(79)$ & $18(63)$ & $20(64.8)$ & $5.1(10.1)$ \\
\hline Preoperative thoracolumbar, ${ }^{\circ}(\%$ flexibility $)$ & $91(20)$ & $78(33)$ & $71(38)$ & $69(31)$ & $77.3(30.5)$ & $9.9(7.6)$ \\
\hline Postoperative thoracolumbar, ${ }^{\circ}(\%$ correction $)$ & $20(78)$ & $29(63)$ & $20(72)$ & $18(74)$ & $21.8(71.8)$ & $4.9(6.3)$ \\
\hline Preoperative lordosis, ${ }^{\circ}$ & 58 & 40 & 71 & 59 & 57 & 12.78 \\
\hline Postoperative lordosis, ${ }^{\circ}$ & 52 & 48 & 68 & 63 & 57.8 & 9.32 \\
\hline CEV & L3 & L3 & L4 & L4 & & \\
\hline Touched vertebra & L4 & L4 & L3 & L4 & & \\
\hline Stable vertebra & L5 & L5 & L5 & L5 & & \\
\hline LIV & L3 & L4 & L3 & L4 & & \\
\hline Distal fusion level saved & Yes & & Yes & & & \\
\hline
\end{tabular}

with unilateral facetectomy and discectomy in multiple levels in the thoracolumbar spine has yet to be established..$^{29}$ Anterior disc release has been shown to significantly increase flexibility and decrease spinal stiffness in cadaveric and animal models. ${ }^{30-31}$

PCDR was able to restore global coronal and sagittal alignment for all 4 patients in this case series at most recent follow-up, with minimal complications. Correction of the major curvature from a mean of $77.3^{\circ}$ to $21.8^{\circ}$ (approximately $71.8 \%$ ) was achieved using PCDR. This is comparable to the range of coronal correction achieved by standard anterior and posterior fusions reported in the current literature from $32 \%$ to $85 \% .^{24,32-34}$ PCDR can be considered an intermediate release for moderately severe curvatures that do not require 3-column osteotomies or a formal anterior release. PCDR has the potential to preserve a distal level, as reported in some anterior procedures, and improves coronal imbalance by $52 \% .^{35,36}$ A distal fusion level was saved in 2 of our 4 patients: one fused cephalad to the CEV and the other one cephalad of the touched and stable vertebrae. One patient was fused 1 level caudal to the CEV because of the presence of disc degeneration at the intervertebral disc caudal to the CEV. LIV tilt was improved from a preoperative mean of $26.8^{\circ}$ to postoperative mean $8.3^{\circ}$, LIV translation from 2.5 to $1.2 \mathrm{~cm}$. No significant complications lasting beyond 3 months occurred.

Reducing the number of fused levels maximizes spinal flexibility and distributes stress across more distal lumbar motion segments, potentially diminishing adjacent segment disc degeneration. ${ }^{10}$ Minimizing the loss of lumbar motion can theoretically reduce the risk of lumbar degeneration or pain. Several biomechanical studies have shown that posterior spinal fusion constructs for thoracolumbar deformity that extend to the lumbar spine can increase the rate of adjacent segment deformity and late back pain. ${ }^{7,21,37,38}$ In this series, the LIV was L3 in 2 patients and L4 in 2 patients. A distal vertebral level was saved in the 28-year-old patient with an LIV of L3 and a CEV of L4. Ideally, fusion constructs should avoid extension beyond L3 to avoid an increased risk of disc degeneration, assuming the remaining unfused caudal motion segments are healthy preoperatively. ${ }^{21}$ Ten-year disc degeneration in AIS has been reported, and an LIV of L4, disc wedging caudad to the LIV $\geq 5$, and LIV translation $\geq 2 \mathrm{~cm}$ were found to be risk factors for disc degeneration. ${ }^{21}$ In the current PCDR series, LIV translation was adequately reduced, although LIV tilt was slightly greater than the targeted goal of $5^{\circ}$ or less. In this case series we showed initial clinical feasibility for this procedure to be able to

Table 3. Changes in measurements.

\begin{tabular}{|c|c|c|c|c|c|c|}
\hline & $17 \mathrm{y} / \mathbf{M}$ & $37 \mathrm{y} / \mathbf{M}$ & $28 \mathrm{y} / \mathrm{F}$ & $45 \mathrm{y} / \mathrm{F}$ & Mean & SD \\
\hline Coronal imbalance preoperative, $\mathrm{cm}$ & 0.97 & 2.7 & 1.09 & 0.85 & 1.4 & 0.9 \\
\hline Coronal imbalance postoperative, $\mathrm{cm}$ & 0.27 & 0.67 & 0.94 & 0.8 & 0.67 & 0.3 \\
\hline LIV tilt & 37 & 28 & 27 & 15 & 26.8 & 9.0 \\
\hline LIV tilt & 7 & 10 & 9 & 7 & 8.3 & 1.5 \\
\hline LIV translation preoperative & 3.75 & 2.7 & 2.41 & 1.19 & 2.5 & 1.1 \\
\hline LIV translation postoperative & 1.4 & 1.53 & 1.76 & 0 & 1.2 & 0.8 \\
\hline Thoracic ATR preoperative & 5 & $\mathrm{NC}$ & 18 & 5 & 9.3 & 7.5 \\
\hline Thoracic ATR postoperative & 6 & 4 & 9 & 0 & 4.8 & 3.8 \\
\hline Thoracolumbar ATR preoperative & 27 & 30 & 15 & 26 & 24.5 & 6.6 \\
\hline Thoracolumbar ATR postoperative & 6 & 2 & 1 & 7 & 4 & 3.0 \\
\hline
\end{tabular}

Abbreviation: NC, not collected. 
save a distal fusion level compared with other techniques. However, because of the limited cases evaluated, we have not shown an ability to routinely save a distal fusion level, and this would require further study with a larger cohort and more extensive follow-up to determine whether long-term outcomes are comparable to those of other techniques.

PCDR has low morbidity in the milieu of techniques to release the spine. A posterior corridor is used, taking advantage of the rotation of the vertebral segment, which delivers the lateral disc and the anterior longitudinal ligament more posteriorly along the convexity of the curvature. At the same time, the spinal cord and/or cauda equina deviate toward the concavity and further away from the operative field. There are potential risks involved with PCDR. Complications were minimal in our series. One patient did experience dysesthesias in the lower extremity on the side of the PCDR, which resolved completely after 2 months and was likely related to irritation of the dorsal root ganglion of an operated segment. Potential drawbacks of this approach include incomplete restoration of lordosis compared with anterior approaches with the use of a structural graft. We have not used this technique to add structural grafts or synthetic structural support, although that could be performed, particularly at the caudal end of the construct to preserve lordosis and stability of the distal segment pedicular fixation. Lumbar lordosis was well maintained in our patients. Other potential complications include durotomy or injury to either viscera or anterior blood vessels when performing the discectomy. The exiting foraminal nerve root is at potential risk, particularly as the root descends and traverses the disc space. We have used a retractor for the exiting and traversing nerve root and a small ribbon malleable retractor to protect the viscera during the release, and this is an area ripe for further development of instruments to facilitate this approach.

In conclusion, severe, rigid thoracolumbar scoliosis may be a challenge to treat in order to achieve optimal 3-dimensional correction while minimizing fusion levels and avoiding procedural morbidity. PCDR is a novel technique that may facilitate this correction with minimal procedure-related morbidity. PCDR appears to be effective as an adjunct procedure to achieve 3-dimensional correction of the thoracolumbar spine without the associated approach-related morbidity of anterior approaches, using a very familiar TLIF approach to achieve disc release. In this series, the procedure was effective in restoring coronal, axial, and sagittal alignment, and it may facilitate saving a distal fusion level in some cases without the addition of a separate anterior exposure. Clinical results have been excellent, with presumed improved correction compared with posterior-only approaches. Further study of this technique is required, including cadaveric biomechanical studies to compare the release to other approaches, development of improved retractors to prevent injury to exiting nerve roots, development of this approach in the thoracic spine, and future studies comparing this technique with a control group without PCDR or with anterior or lateral approaches.

\section{REFERENCES}

1. Hempfing A, Ferraris L, Koller H, Rump J, MetzStavenhagen P. Is anterior release effective to increase flexibility in idiopathic thoracic scoliosis?: assessment by traction films Eur Spine J. 2007;16(4):515-520.

2. Verma K, Lonner BS, Kean KE, Dean LE, Valdevit A. Maximal pulmonary recovery after spinal fusion for adolescent idiopathic scoliosis: how do anterior approaches compare? Spine (Phila Pa 1976). 2011;36(14):1086-1095.

3. Wang Y, Fei Q, Qiu G, Lee CI, Shen J, Zhang J, et al. Anterior spinal fusion versus posterior spinal fusion for moderate lumbar/thoracolumbar adolescent idiopathic scoliosis: a prospective study. Spine (Phila Pa 1976). 2008;33(20):21662172.

4. Wollowick AL, Farrelly EE, Meyers K, Grossman S, Amaral TD, Wright T, et al. Anterior release generates more thoracic rotation than posterior osteotomy: a biomechanical study of human cadaver spines. Spine (Phila Pa 1976). 2013;38(18):1540-1545.

5. Weiss HR, Goodall D. Rate of complications in scoliosis surgery-a systematic review of the Pub Med literature. Scoliosis. 2008;3:9.

6. Aaro S, Ohlund C. Scoliosis and pulmonary function. Spine (Phila Pa 1976). 1984;9(2):220-222.

7. Di Silvestre M, Bakaloudis G, Lolli F, Vommaro F, Martikos K, Parisini P. Posterior fusion only for thoracic adolescent idiopathic scoliosis of more than 80 degrees: pedicle screws versus hybrid instrumentation. Eur Spine J. 2008;17(10):1336-1349.

8. Dobbs MB, Lenke LG, Kim YJ, Luhmann SJ, Bridwell KH. Anterior/posterior spinal instrumentation versus posterior instrumentation alone for the treatment of adolescent idiopathic scoliotic curves more than 90 degrees. Spine (Phila Pa 1976). 2006;31(20):2386-2391.

9. Kim YJ, Lenke LG, Bridwell KH, Cheh G, Sides B, Whorton J. Prospective pulmonary function comparison of anterior spinal fusion in adolescent idiopathic scoliosis: thoracotomy versus thoracoabdominal approach. Spine (Phila Pa 1976). 2008;33(10):1055-1060. 
10. Luhmann SJ, Lenke LG, Kim YJ, Bridwell KH, Schootman M. Thoracic adolescent idiopathic scoliosis curves between 70 degrees and 100 degrees: is anterior release necessary? Spine (Phila Pa 1976). 2005;30(18):2061-2067.

11. Shufflebarger HL, Geck MJ, Clark CE. The posterior approach for lumbar and thoracolumbar adolescent idiopathic scoliosis: posterior shortening and pedicle screws. Spine (Phila Pa 1976). 2004;29(3):269-276; discussion 276.

12. Betz RR, Harms J, Clements DH 3rd, Lenke LG, Lowe TG, Shufflebarger HL, et al. Comparison of anterior and posterior instrumentation for correction of adolescent thoracic idiopathic scoliosis. Spine (Phila Pa 1976). 1999;24(3):225-239.

13. Burton DC, Asher MA, Lai SM. Patient-based outcomes analysis of patients with single torsion thoracolumbar-lumbar scoliosis treated with anterior or posterior instrumentation: an average 5- to 9-year follow-up study. Spine (Phila Pa 1976). 2002;27(21):2363-2367.

14. Hee HT, Yu ZR, Wong HK. Comparison of segmental pedicle screw instrumentation versus anterior instrumentation in adolescent idiopathic thoracolumbar and lumbar scoliosis. Spine (Phila Pa 1976). 2007;32(14):1533-1542.

15. Lonner BS, Auerbach JD, Estreicher M, Milby AH, Kean KE, Panagopoulos G, et al. Video-assisted anterior thoracoscopic spinal fusion versus posterior spinal fusion: a comparative study utilizing the SRS-22 outcome instrument. Spine (Phila Pa 1976). 2009;34(2):193-198.

16. Bridwell KH, Lewis SJ, Rinella A, Lenke LG, Baldus C, Blanke K. Pedicle subtraction osteotomy for the treatment of fixed sagittal imbalance: surgical technique. J Bone Joint Surg Am. 2004;86A(suppl 1):44-50.

17. Balderston RA, Albert TJ, McIntosh T, Wong L, Dolinskas C. Magnetic resonance imaging analysis of lumbar disc changes below scoliosis fusions: a prospective study. Spine (Phila Pa 1976). 1998;23(1):54-58; discussion 59.

18. Bridwell $\mathrm{KH}$. Where to stop the fusion distally in adult scoliosis: L4, L5, or the sacrum? Instr Course Lect. 1996;45:101107.

19. Danielsson AJ, Cederlund CG, Ekholm S, Nachemson AL. The prevalence of disc aging and back pain after fusion extending into the lower lumbar spine: a matched MR study twenty-five years after surgery for adolescent idiopathic scoliosis. Acta Radiol. 2001;42(2):187-197.

20. Schwab F, Blondel B, Chay E, Demakakos J, Lenke L, Tropiano P, et al. The comprehensive anatomical spinal osteotomy classification. Neurosurgery. 2015;76(suppl 1):S33S41; discussion S41.

21. Lonner BS, Ren Y, Upasani VV, Marks MM, Newton PO, Samdani AF, Chen K, Shufflebarger HL, Shah SA, Lefton DR, Nasser H, Dabrowski CT, Betz RR. Disc degeneration in unfused caudal motion segments ten years following surgery for adolescent idiopathic scoliosis. Spine Deformity. 2018; 6(6):684690 .

22. Wang C, Bell K, McClincy M, Jacobs L, Dede O, Roach $\mathrm{J}$, et al. Biomechanical comparison of ponte osteotomy and discectomy. Spine (Phila Pa 1976). 2015;40(3):E141-E145.

23. Bernstein RM, Hall JE. Solid rod short segment anterior fusion in thoracolumbar scoliosis. $J$ Pediatr Orthop $B$. 1998;7(2):124-131. Epub 1998/05/23. PubMed PMID: 9597587.

24. O'Donnell C, Michael N, Pan X, Emans J, Garg S, Erickson M. Anterior spinal fusion and posterior spinal fusion both effectively treat lenke type 5 curves in adolescent idiopathic scoliosis: a multicenter study. Spine Deform. 2018;6(3):231-240.

25. Li M, Ni J, Fang $\mathrm{X}$, Liu $\mathrm{H}$, Zhu $\mathrm{X}$, He S, et al. Comparison of selective anterior versus posterior screw instrumentation in Lenke $5 \mathrm{C}$ adolescent idiopathic scoliosis. Spine. 2009;34(11):1162-1166.

26. Geck MJ, Rinella A, Hawthorne D, Macagno A, Koester L, Sides B, et al. Anterior dual rod versus posterior pedicle fixation surgery for the surgical treatment in Lenke $5 \mathrm{C}$ adolescent idiopathic scoliosis: a multicenter, matched case analysis of 42 patients. Spine Deform. 2013;1(3):217-222.

27. Burton DC, Sama AA, Asher MA, Burke SW, BoachieAdjei O, Huang $\mathrm{RC}$, et al. The treatment of large $\left(>70^{\circ}\right)$ thoracic idiopathic scoliosis curves with posterior instrumentation and arthrodesis: when is anterior release indicated? Spine. 2005;30(17):1979-1984.

28. Erdem MN, Karaca S, Korkmaz MF, Enercan M, Tezer M, Kara AN, et al. Criteria for ending the distal fusion at the L3 vertebra vs. L4 in surgical treatment of adolescent idiopathic scoliosis patients with Lenke type $3 \mathrm{C}, 5 \mathrm{C}$, and 6C curves: results after ten years of follow-up. Cureus. 2018;10(5):e2564.

29. Auerbach JD, Lenke LG, Bridwell KH, Sehn JK, Milby $\mathrm{AH}$, Bumpass D, et al. Major complications and comparison between 3-column osteotomy techniques in 105 consecutive spinal deformity procedures. Spine (Phila Pa 1976). 2012;37(14):1198-1210.

30. Feiertag MA, Horton WC, Norman JT, Proctor FC, Hutton WC. The effect of different surgical releases on thoracic spinal motion: a cadaveric study. Spine (Phila Pa 1976). 1995;20(14):1604-1611.

31. Newton PO, Cardelia JM, Farnsworth CL, Baker KJ, Bronson DG. A biomechanical comparison of open and thoracoscopic anterior spinal release in a goat model. Spine (Phila Pa 1976). 1998;23(5):530-535; discussion 536.

32. Geck MJ, Rinella A, Hawthorne D, Macagno A, Koester L, Sides B, Bridwell K, et al. Comparison of surgical treatment in Lenke $5 \mathrm{C}$ adolescent idiopathic scoliosis: anterior dual rod versus posterior pedicle fixation surgery: a comparison of two practices. Spine. 2009;34(18):1942-1951.

33. Matsumoto M, Watanabe K, Hosogane N, Kawakami $\mathrm{N}$, Tsuji T, Uno K, et al. Postoperative distal adding-on and related factors in Lenke type 1A curve. Spine. 2013;38(9):737744.

34. Lowe TG, Alongi PR, Smith DAB, O'Brien MF, Mitchell SL, Pinteric RJ. Anterior single rod instrumentation for thoracolumbar adolescent idiopathic scoliosis with and without the use of structural interbody support. Spine. 2003;28(19):2232-2241.

35. Lowe TG, Betz R, Lenke L, Clements D, Harms J, Newton $\mathrm{P}$, et al. Anterior single-rod instrumentation of the thoracic and lumbar spine: saving levels. Spine. 2003;28(20S):208-216.

36. Luo M, Wang W, Shen M, Xia L. Anterior versus posterior approach in Lenke $5 \mathrm{C}$ adolescent idiopathic scoliosis: a meta-analysis of fusion segments and radiological outcomes. $J$ Orthop Surg Res. 2016;11(1):77.

37. Lonner BS, Auerbach JD, Estreicher MB, Betz RR, Crawford AH, Lenke LG, et al. Pulmonary function changes after various anterior approaches in the treatment of adolescent idiopathic scoliosis. J Spinal Disord Tech. 2009;22(8):551-558.

38. Verma K, Auerbach JD, Kean KE, Chamas F, 
Vorsanger M, Lonner BS. Anterior spinal fusion for thoracolumbar scoliosis: comprehensive assessment of radiographic, clinical, and pulmonary outcomes on 2-years follow-up. $J$ Pediatr Orthop. 2010;30(7):664-669.

Disclosures and COI: The authors received no funding for this study and report no conflicts of interest.

Corresponding Author: Baron S. Lonner, MD, Orthopaedic Surgery, Mount Sinai Hospital, 5
E $98^{\text {th }}$ St, New York, NY 10029. Phone: (212) 2418312; Fax: (646) 537-9449; Email: baron.lonner@ mountsinai.org.

Published 30 June 2020

This manuscript is generously published free of charge by ISASS, the International Society for the Advancement of Spine Surgery. Copyright (C) 2020 ISASS. To see more or order reprints or permissions, see http://ijssurgery.com. 